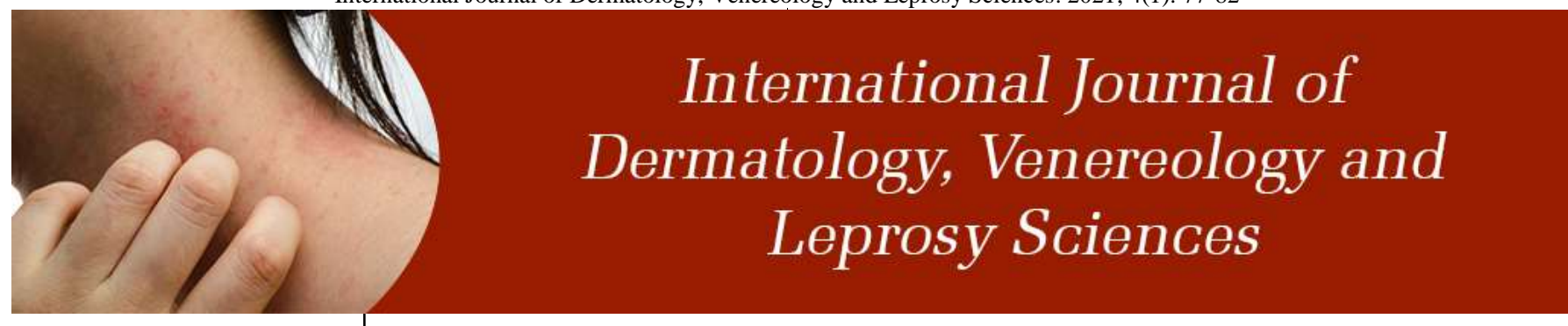

E-ISSN: 2664-942X

P-ISSN: 2664-9411

www.dermatologypaper.com

Derma 2021; 4(1): 77-82

Received: 06-11-2020

Accepted: 12-12-2020

Dr. Vidyasagar

Associate Professor,

Department of DVL.KIMS

Hospital, Narketpally,

Telangana, India

Dr. Vijaybhskar Reddy

Assistant Professor,

Department of DVL.KIMS

Hospital, Narketpally,

Telangana, India

Dr. Navaneetha Rddy Assistant Professor, Department of DVL.KIMS Hospital, Narketpally, Telangana, India
Corresponding Author:

Dr. Vidyasagar

Associate Professor,

Department of DVL.KIMS

Hospital, Narketpally,

Telangana, India

\section{Efficacy of intralesional MMR vaccine for the management of cutaneous warts in adults}

\author{
Dr. Vidyasagar, Dr. Vijaybhskar Reddy and Dr. Navaneetha Rddy
}

DOI: https://doi.org/10.33545/26649411.2021.v4.i1b.71

\begin{abstract}
Background: No single treatment for warts has proven $100 \%$ efficacy and most therapeutic modalities remain unsatisfactory. Immunotherapy with Measles-Mumps-Rubella (MMR) vaccine remains a key treatment of interest.

The study done from August 2020 to March 2021 in the department of Dermatology, KIMS hospital, Narketpally. Telangana state.

Objective: To evaluate the efficacy of intralesional MMR vaccine in the treatment of cutaneous warts in adults.

Patients and Methods: Fifty patients ( 34 men and 16 women) aged 18-61 (mean \pm standard deviation $=34.58 \pm 11.74$ ) years with common warts received $0.25 \mathrm{ml}$ of MMR vaccine injected intralesionally in the largest wart. The dose was repeated at 2-week interval until complete clearance or for a maximum of 5 doses. Thereafter, they were followed up once a month for 24 -week study period. The response was evaluated as complete clearance (complete disappearance of the wart(s) including distant ones and appearance of normal skin), partial clearance ( $\leq 99 \%$ reduction in size and number including distant ones and few residual warts still visible), good response (some reduction in size only including that of distant ones but no decrease in number of warts), or poor response (no change in size and number)

Results: 50 patients completed the study and $29(58 \%)$ of them had complete clearance of warts, 14 $(28 \%)$ showed partial clearance and $5(10 \%)$ patients showed good response. Complete clearance of warts occurred after five doses in $19(38 \%)$ patients and after 4 doses in $9(18 \%)$ patients.

Conclusion: MMR vaccine is a promising treatment modality for common warts, particularly the multiple and recalcitrant ones. It seems to be inexpensive, effective and safe option that has the potential advantages of widespread and sustained effects against HPV. Intralesional MMR also appears to be much less painful and safe than traditional destructive methods for wart treatment, and thus seems to be better tolerated.
\end{abstract}

Keywords: MMR vaccine, $100 \%$ efficacy, KIMS hospital

\section{Introduction}

Cutaneous warts or verruca vulgaris are hyperkeratotic papillomas due to human papilloma virus (HPV) infection. They frequently occur over hands of children and young adults but may be located on any cutaneous or mucosal surface. Although spontaneous recovery occurs, it usually takes a long time and even years.

Treatment of warts becomes a challenge when they are numerous or present over inaccessible areas. There are many ablative modalities of therapy such as electrocautery, chemical cautery, cryotherapy, laser surgery, curettage and topical keratolytics. Most of these take months and many of them may result in pain, scarring, and recurrences [1]. Ablative therapies are also limited by the fact that they only remove visible lesions; non-visible infected tissues are not targeted, resulting in a high chance of recurrence ${ }^{[2]}$. The other type of therapy is immunotherapy which is based on the activation of the immune system to deal with the virus and suppress its activity. Such therapy may be applied either topically or through intralesional injection or through systemic administration ${ }^{[3]}$.

In this study we treated patients with intralesional immunotherapy with MMR vaccine. It has the potential advantages of clearance of both treated and untreated distant warts without scarring, a presumed low rate of recurrence, and a high safety profile. Although the mechanism of effectiveness of intralesional injection of MMR vaccine and antigens has not yet been known, it seems that nonspecific inflammatory response to the antigens is the major mechanism of immunotherapy ${ }^{[4]}$. 


\section{Patients and Methods}

The study enrolled 50 adults diagnosed with common warts for the study after informed written consent. Demographic and clinical details for number and size of warts and sites involved were recorded. Photographic records were made prior to treatment (at baseline) and at each subsequent visit. Immunocompromised, pregnant and lactating mothers and patients below 18 years of age were excluded.

All enrolled patients were given freeze-dried MMR vaccine. The vaccine was reconstituted with $0.5 \mathrm{~mL}$ of provided diluent (distilled water) immediately before intralesional use. All enrolled patients received intralesional injection of $0.25 \mathrm{~mL}$ of reconstituted MMR vaccine in largest wart with $30 \mathrm{G}$ insulin syringe (one dose). The dose was repeated at every 2 -week interval in a similar fashion until complete clearance or for a maximum of five doses. Thereafter, they were followed up once a month for 24-week study period Out of 50 patients only few patients followed the stipulated schedule; most of the patients came one or three days after the scheduled period. Few patients came after complete clearing of the lesions.

All treated patients were evaluated by an independent blinded observer and by comparing clinical photographic records at each treatment session for decrease in size and number of warts and any immediate side effects, if any. Resolution of distant untreated warts was also assessed. The clinical improvement was rated by using Visual Analog Scale (VAS) score at each visit taking baseline clinical photograph as controls. The response was evaluated as complete clearance (VAS score 100, complete disappearance of the wart(s) including distant ones and appearance of normal skin), partial clearance (VAS score $75 \%-99 \%, \leq 99 \%$ reduction in size and number including distant ones and few residual warts still visible), good response (VAS score 50\%-75\%), some reduction in size only including that of distant ones but no decrease in number of warts) or poor response (VAS score $<50$, no change in size and number.

\section{Results}

The study included 34 men and 16 women $(\mathrm{M}: \mathrm{F}=2.1: 1)$ aged between 19 years to 61 years (mean \pm standard deviation $[\mathrm{SD}]=34.58 \pm 11.74$ ) years. The majority, 29 (58\%) patients were aged between 21 and 40 years. The duration of warts was 1 month to 72 (mean \pm SD $=15.52 \pm$ 14.65) months and the number varied from a solitary in 2 patients to 42 warts in a single patient (mean $\pm \mathrm{SD}=11.8 \pm$ 10.30) localized mainly over dorsal hands and feet, and soles (in 25 patients), periungual skin (in 2 patients), and multiple sites including hands and face in three patients. No patient had received any treatment for warts previously. Table No depicts therapeutic outcome; overall, in 50 patients who completed the study warts showed complete clearance in $29(58 \%)$ and partial clearance occurred in 14 $(28 \%)$ patients, good clearance was seen in $5(10 \%)$ patients and poor response was seen in $2(4 \%)$ patients during 9 months of study period. Complete clearance of warts occurred after five doses in $19(38 \%)$ patients and after 4 doses in $9(18 \%)$ patients. All patients experienced mild-tomoderate injection site pain at the time of MMR vaccine injection that did not warrant discontinuation of treatment. There were no systemic adverse effects, scarring, or residual pigmentation. MMR vaccine injection for periungual warts did not adversely affect nail growth or caused onycholysis or nail dystrophy. No recurrence of warts was noted among cured at the end of the study period. All cured patients were very much satisfied (score of 5 on Likert scale) from treatment.

Table 1: Gender distribution of patients in the study

\begin{tabular}{|c|c|}
\hline Gender & Number of patients $(\mathbf{n}=\mathbf{5 0})$ \\
\hline Men & 34 \\
\hline Women & 16 \\
\hline Men:Women & $2.1: 1$ \\
\hline
\end{tabular}

Table 2: Age distribution of patients in the study

\begin{tabular}{|c|c|}
\hline Age (years) range, mean $\mathbf{\pm}$ SD & $\mathbf{3 4 . 5 8} \pm \mathbf{1 1 . 7 4}$ \\
\hline$<20$ & 3 \\
\hline $21-40$ & 29 \\
\hline $41-60$ & 17 \\
\hline$>60$ & 1 \\
\hline
\end{tabular}

Table 3: Number of warts

\begin{tabular}{|c|c|}
\hline Range, mean $\mathbf{\pm}$ SD & $\mathbf{1 1 . 8} \mathbf{\pm 1 0 . 3 0}$ \\
\hline $1-10$ & 28 \\
\hline $11-20$ & 13 \\
\hline $21-30$ & 5 \\
\hline $31-40$ & 3 \\
\hline$>40$ & 1 \\
\hline
\end{tabular}

Table 4: Duration of warts in months

\begin{tabular}{|c|c|}
\hline Range, mean $\mathbf{\pm}$ SD & $\mathbf{1 5 . 5 2} \pm \mathbf{1 4 . 6 5}$ \\
\hline $1-12$ & 18 \\
\hline $13-24$ & 23 \\
\hline $25-36$ & 4 \\
\hline $37-48$ & 2 \\
\hline $49-60$ & 2 \\
\hline$>60$ & 1 \\
\hline
\end{tabular}

Table 5: Site of warts

\begin{tabular}{|c|c|}
\hline Site of warts & Number of patients $(\mathbf{n}=\mathbf{5 0})$ \\
\hline Dorsum of Hand/Foot & $25(50 \%)$ \\
\hline Palmoplantar & $20(40 \%)$ \\
\hline Periungual skin & $2(4 \%)$ \\
\hline Multiple sites & $3(6 \%)$ \\
\hline
\end{tabular}

Table 6: Grades of clinical improvement after intralesional MMR vaccine

\begin{tabular}{|c|c|}
\hline Grade & Number of patients $(\mathbf{n}=\mathbf{5 0})$ \\
\hline Complete $(\mathrm{VAS}=100 \%)$ & $29(58 \%)$ \\
\hline Partial (VAS $=75 \%-99 \%)$ & $14(28 \%)$ \\
\hline Good (VAS = 50\%-75\%) & $5(10 \%)$ \\
\hline Poor (VAS < 50\%) & $2(4 \%)$ \\
\hline
\end{tabular}

\section{Discussion}

The exact mechanism of effectiveness of intralesional injection of MMR vaccine or antigen in warts remains hypothetical. It is possible that it accelerates the clearance of virus and viral infected cells by stimulation of CMI and humoral immunity that is suggested to play a significant role in the pathogenesis and persistence of warts or perhaps the nonspecific inflammatory response to the antigens is the major mechanism of immunotherapy ${ }^{[4-7]}$.

Nofal and Nofal ${ }^{[8]}$ reported cure rates of $81.4 \%$ patients as compared with $27.5 \%$ in placebo group with intralesional MMR vaccine and antigens. Similar results were also reported by Mohamad et al. ${ }^{[9]}$ and Zamanian et al. 
${ }^{[7]}$ separately observing complete clearance in $82 \%$, partial response in $6 \%$, and no response in $12 \%$ patients of plantar warts, and complete cure of common warts in $75 \%$, relative cure in $16.66 \%$ and no cure in $8.33 \%$ patients, respectively. $\mathrm{Na}$ et al. ${ }^{[4]}$ also observed decrease in size of warts in $51 \%$ of 136 patients, while complete resolution occurred in $5.6 \%$ of patients. Intralesional immunotherapy with MMR was superior with clearance rates of $80 \%$ and $40 \%$ with MMR, $60 \%$ with purified protein derivative, and $0 \%$ with saline in 10 patients each and to cauterization with $100 \%$ TCA in two separate studies, respectively ${ }^{[10,11]}$.

At present there is no consensus for a minimum dose of MMR vaccine, dosing frequency, and duration of therapy to treat warts ${ }^{[4,7-17]}$. Invariably, three to six doses of $0 .-0.5 \mathrm{~mL}$ administered at intervals of 2-3 weeks have been used with outcome as varied. For instance, three doses of $0.5 \mathrm{~mL}$ injected once in 3 weeks for up to three doses resulted in complete clearance in only $87 \%$ of plantar warts patients, whereas 5 intralesional doses of $0.3 \mathrm{~mL}$ given once in 2 weeks lead to complete resolution in only $63 \%$ of 65 patients in two separate studies ${ }^{[13,14]}$.

\section{Conclusion}

MMR vaccine is a promising treatment modality for common warts, particularly the multiple and recalcitrant ones. It seems to be inexpensive, effective and safe option that has the potential advantages of widespread and sustained effects against HPV. Intralesional MMR also appears to be much less painful and safe than traditional destructive methods for wart treatment, and thus seems to be better tolerated. Even though we were limited by sample size and lack of placebo or other therapeutic group for comparison, the results based on observation give us a potential idea about the effectiveness of this treatment modality.

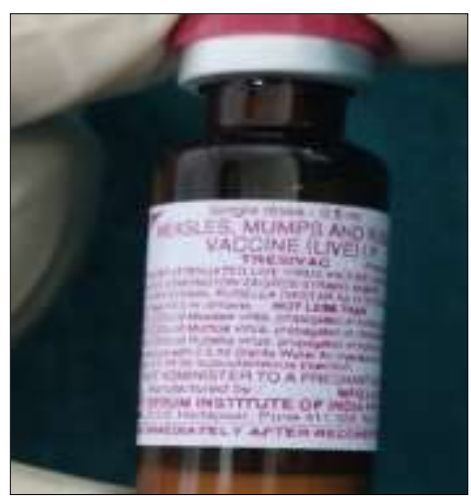

Patient 1 (23 Years/M)

$1^{\text {st }}$ visit (Date: 08.04 .2020$)$

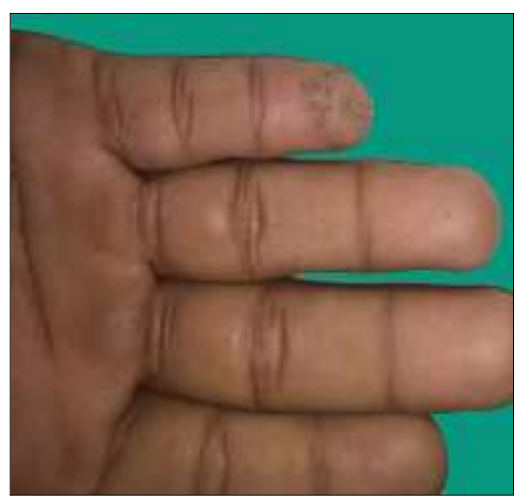

$2^{\text {nd }}$ visit (Date: 23.04 .2020 )

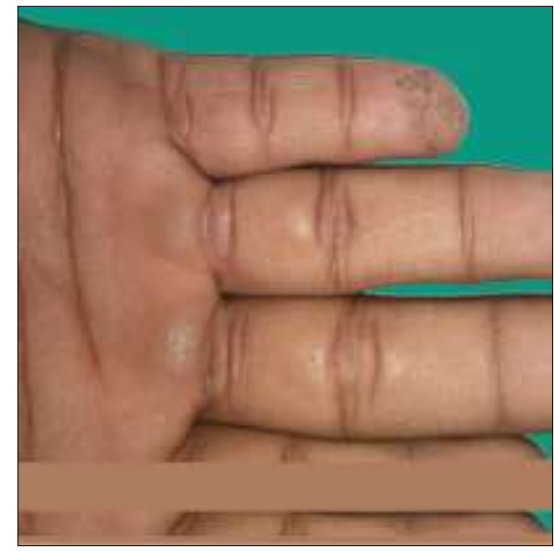

$3^{\text {rd }}$ visit (Date: 12.05 .2020$)$

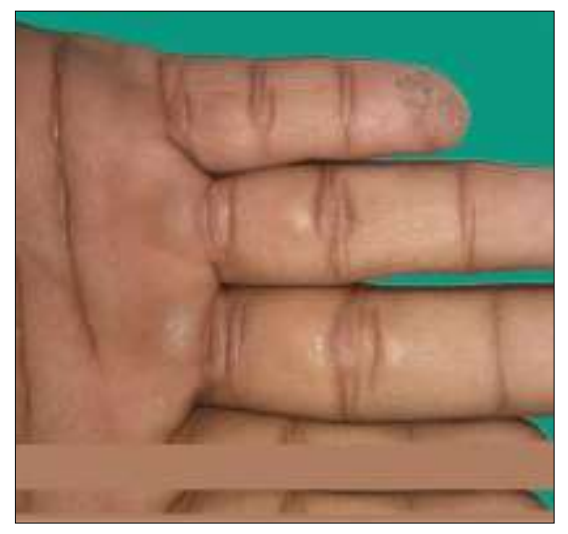

$4^{\text {th }}$ visit (Date: 26.0 .2020$)$

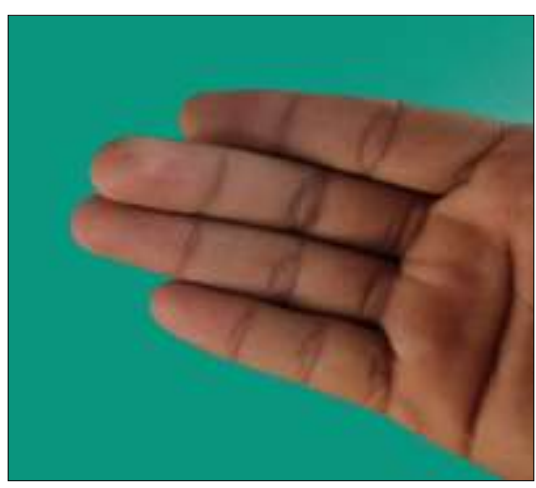

Patient 2 (20 Years / M)

$1^{\text {st }}$ Visit (Date: 02.06 .2020 )

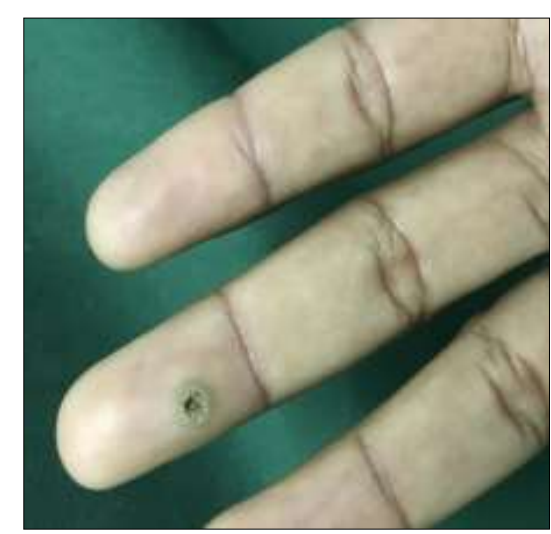


$2^{\text {nd }}$ Visit (Date: 29.06.2020)

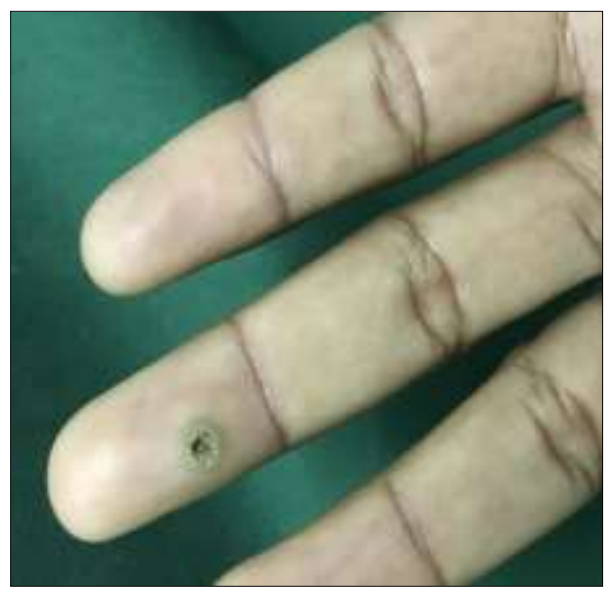

$3^{\text {rd }}$ Visit (Date: 14.08 .2020 )

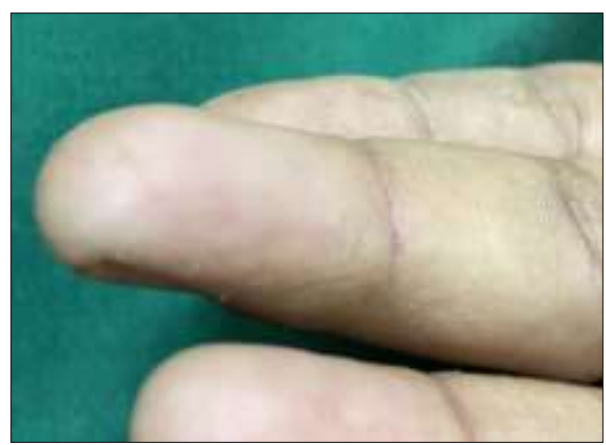

Same Patient as above

$1^{\text {st }}$ Visit (Date: 02.06.2019)

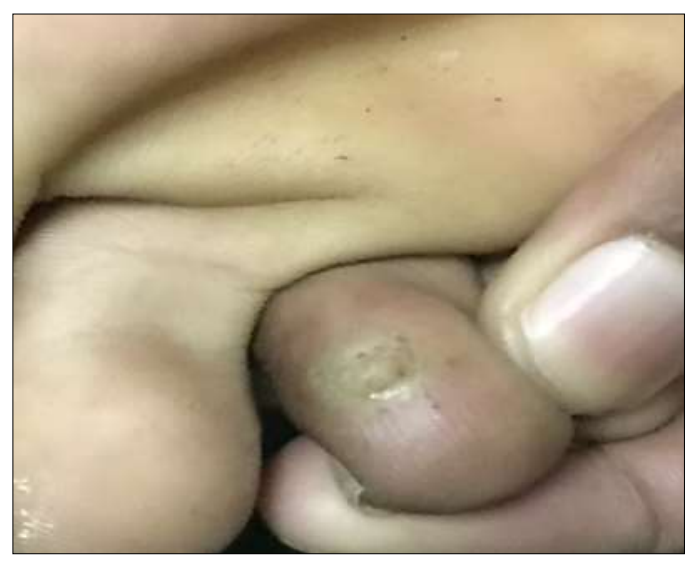

$2^{\text {nd }}$ Visit (Date: 29.06.2020)

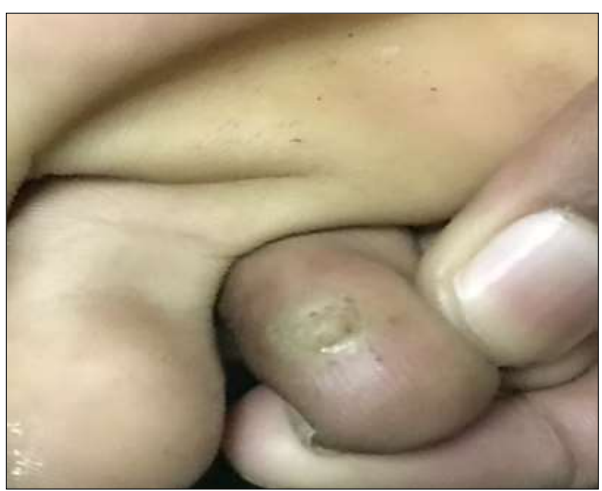

$3^{\text {rd }}$ Visit (Date: 14.08.2020)

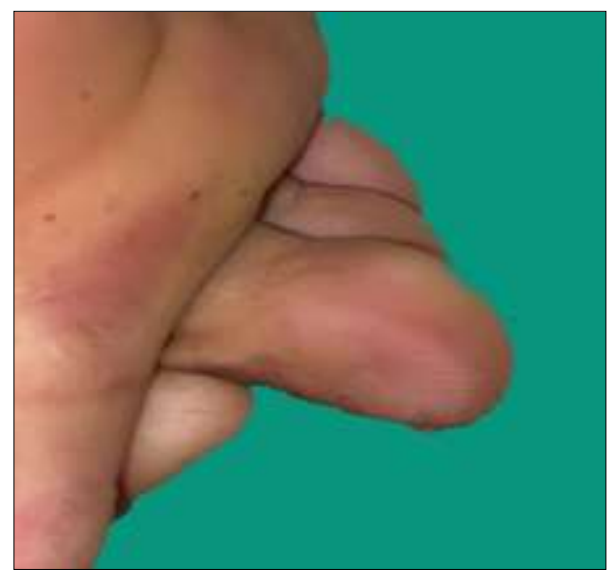

Patient - 3 (19 Years / F)

$1^{\text {st }}$ Visit (Date: 19.06.2020)

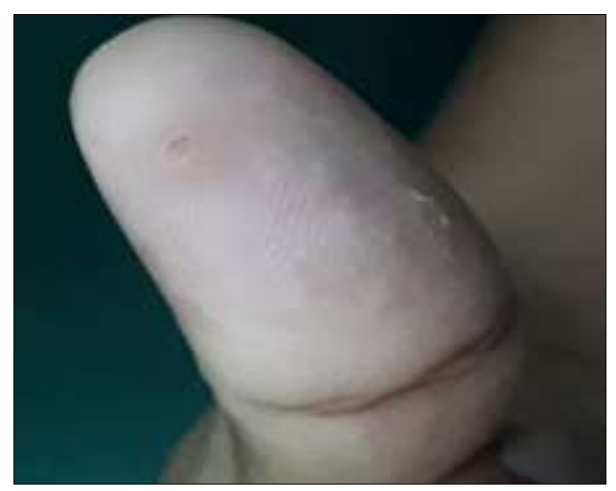

$2^{\text {nd }}$ Visit (Date: 14.07 .2020$)$

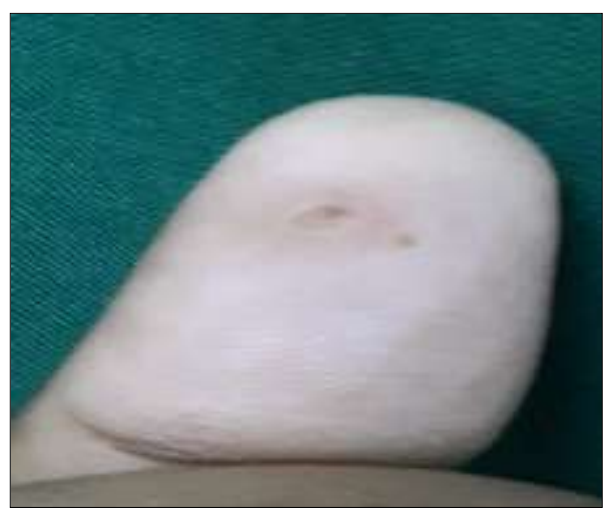

$3^{\text {rd }}$ Visit (Date: 03.08.2020)

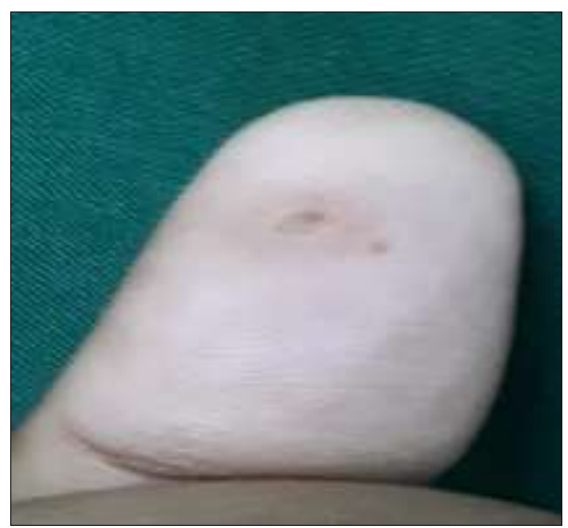




\section{$4^{\text {th }}$ Visit (Date: 26.08.2020)}

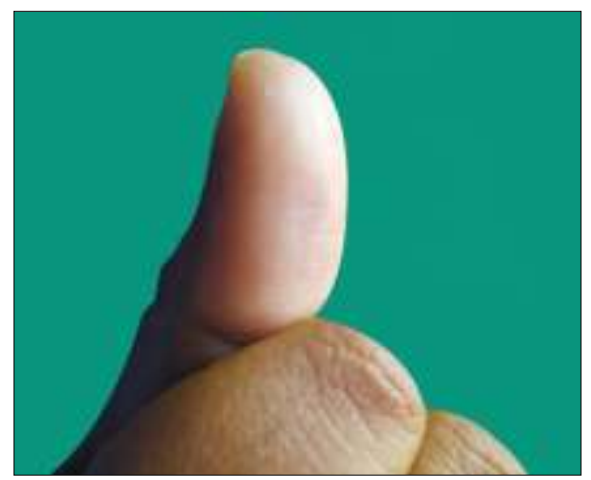

Patient 4 (25 Years / M)

$1^{\text {st }}$ Visit (Date. 02.09.2020)

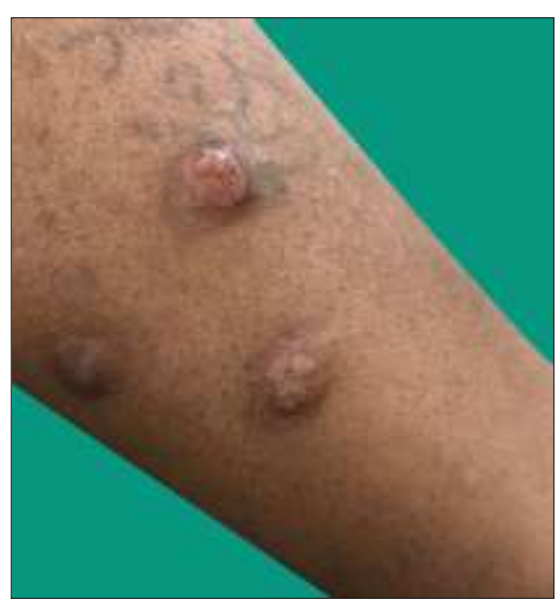

$2^{\text {nd }}$ Visit (Date. 18.09.2020)

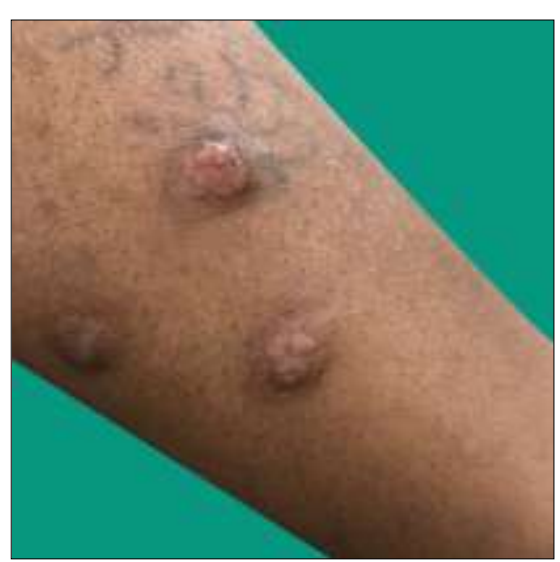

$3^{\text {rd }}$ Visit (Date.06.10.2020)

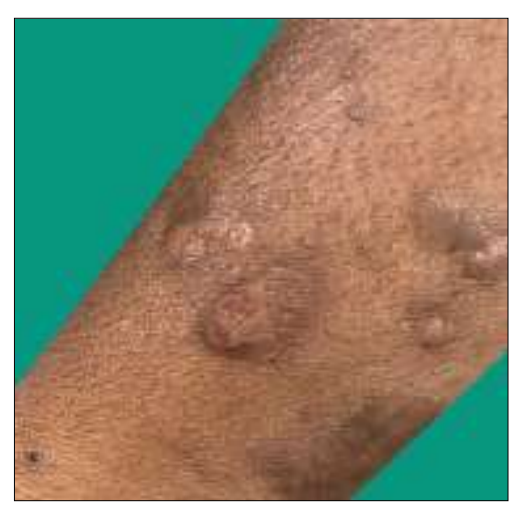

$4^{\text {th }}$ Visit (Date.29.10.2020)

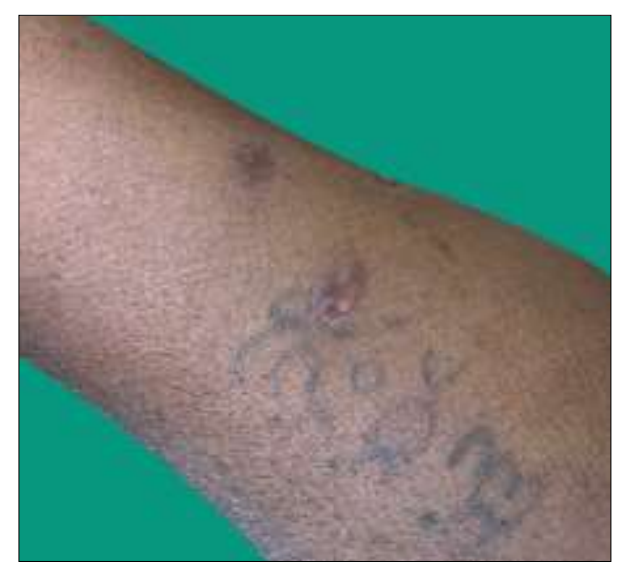

Patient 5 (22 Years / M)

$1^{\text {st }}$ Visit (Date: 05.11.2021)

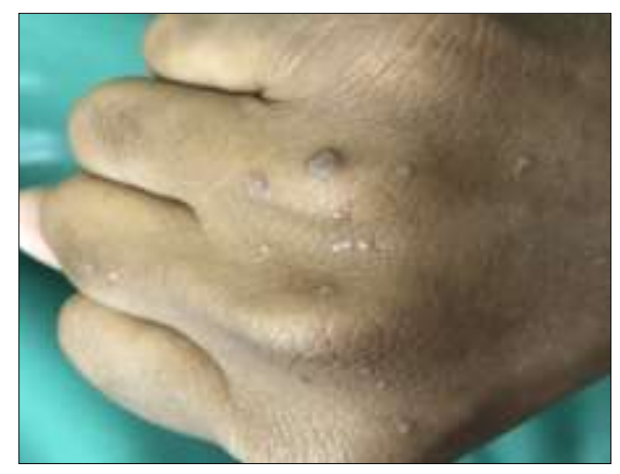

$2^{\text {nd }}$ Visit (Date: 27.11 .2020$)$

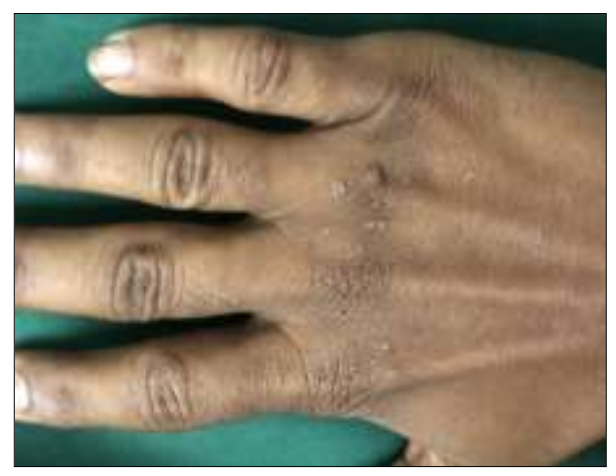

Patient 6 (25 Years / M)

$1^{\text {st }}$ Visit (Date: 05.01.2021)

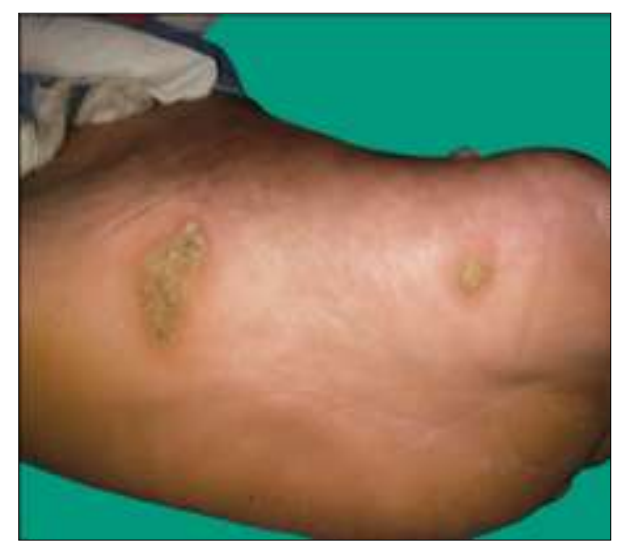




\section{$2^{\text {nd }}$ Visit (Date: 19.03.21)}

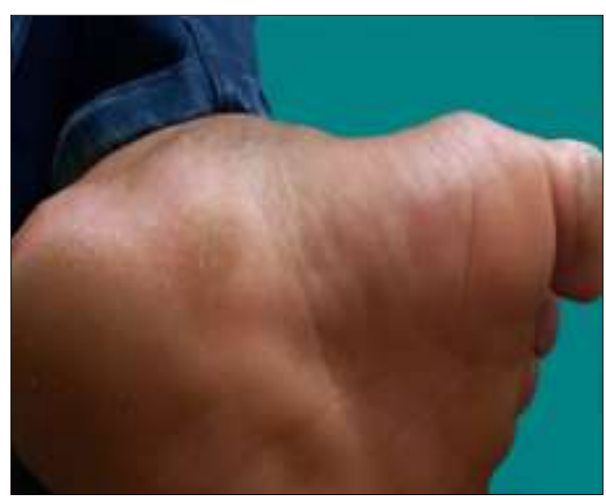

\section{References}

1. Signore RJ. Candida albicans intralesional injection immunotherapy of warts. Cutis 2002;70:185-92.

2. Nofal A, Salah E, Nofal E, Yosef A. Intralesional antigen immunotherapy for the treatment of warts: Current concepts and future prospects. Am J Clin Dermatol 2013;14:253-60.

3. Allen AL, Siegfried EC. Management of warts and molluscum in adolescents. Adolesc Med 2001;12:229242.

4. Na CH, Choi H, Song SH, Kim MS, Shin BS. Two-year experience of using the measles, mumps and rubella vaccine as intralesional immunotherapy for warts. Clin Exp Dermatol 2014;39:583-589.

5. Silverberg NB, Lim JK, Paller AS, Mancini AJ. Squaric acid immunotherapy for warts in children. J Am Acad Dermatol 2000;42:803-8.

6. Gonçalves MA, Donadi EA. Immune cellular response to HPV: Current concepts. Braz J Infect Dis 2004;8:1-9.

7. Zamanian A, Mobasher P, Jazi GA. Efficacy of intralesional injection of mumps-measles-rubella vaccine in patients with wart. Adv Biomed Res 2014;3:107.

8. Nofal A, Nofal E. Intralesional immunotherapy of common warts: Successful treatment with mumps, measles and rubella vaccine. J Eur Acad Dermatol Venereol 2010;24:1166-70.

9. Mohamad NS, Badran F, Yakout E. Evaluation of the efficacy of a combination - Measles, mumps and rubella vaccine in the treatment of plantar warts. Our Dermatol Online 2013;4:463-7.

10. Shaheen MA, Salem SA, Fouad DA, El-Fatah AA. Intralesional tuberculin (PPD) versus measles, mumps, rubella (MMR) vaccine in treatment of multiple warts: A comparative clinical and immunological study. Dermatol Ther 2015;28:194-200.

11. Saini S, Dogra N, Dogra D. A prospective randomized open label comparative study of efficacy and safety of intralesional measles, mumps, rubella vaccine versus $100 \%$ trichloroacetic acid application in the treatment of common warts. Int J Res Med Sci 2016;4:1529-33.

12. Saini S, Dogra N, Dogra D. A prospective randomized open label comparative study of efficacy and safety of intralesional measles, mumps, rubella vaccine versus $100 \%$ trichloroacetic acid application in the treatment of common warts. Int J Res Med Sci 2016;4:1529-33.

13. Gamil H, Elgharib I, Nofal A, Abd-Elaziz T. Intralesional immunotherapy of plantar warts: Report of a new antigen combination. J Am Acad Dermatol

\section{0;63:40-3.}

14. Nofal A, Nofal E, Yosef A, Nofal H. Treatment of recalcitrant warts with intralesional measles, mumps, and rubella vaccine: A promising approach. Int $\mathrm{J}$ Dermatol 2015;54:667-71.

15. Naseem R, Aamir S. The efficacy of intralesional measles, mumps, rubella (MMR) antigen in treatment of common warts. Pak J Med Health Sci 2013;7:11303.

16. Raju J, Swamy AV, Nanjunda Swamy BL, Raghavendra KR. Intralesional measles, mumps and rubella (MMR) vaccine - An effective therapeutic tool in the treatment of wart. J Evid Based Med Healthc 2015;2:8548-51.

17. Shah AN, Patel D, Ravishankar V. Measles, mumps and rubella vaccine as an intralesional immunotherapy in treatment of warts. Int J Res Med Sci 2016;4:472-6. 